\title{
Antioxidant Activity of the Chemical Constituents Isolated from the Roots of Albizia ferruginea (Guill. \& Perr.) Benth. (Fabaceae)
}

\author{
Y.O. Nganso Ditchou',*, C.D. Abah Kombo ${ }^{1}$, M.T.G. Mala Opono², B. Nyasse ${ }^{3}$ \\ ${ }^{1}$ Department of Chemistry, Faculty of Science, University of Maroua, P.O. Box 814, Maroua, Cameroon. \\ ${ }^{2}$ Department of Biochemistry, Faculty of Science, University of Yaounde I, P.O. Box 812, Yaounde, Cameroon. \\ ${ }^{3}$ Department of Organic Chemistry, Faculty of Science, University of Yaounde I, P.O. Box 812, Yaounde, Cameroon.
}

\section{ART I C LEDETAILS}

Article history:

Received 20 June 2019

Accepted 12 July 2019

Available online 21 August 2019

\section{Keywords:}

Albizia ferruginea

Antioxidant Activities

Fabaceae

Secondary Metabolites

\begin{abstract}
A B S T R A C T
The present study was carried out to evaluate the antioxidant activity of chemical constituents isolated from Albizia ferruginea grapes, a plant of the Fabaceae family. The plant is used in traditional pharmacopoeia to treat dysentery, bronchial infections, infections from stings, gallbladder caused by fever and intestinal problems. Chemical study of the $\mathrm{CH}_{2} \mathrm{Cl}_{2}-\mathrm{MeOH}(1: 1)$ extract led to the isolation of six compounds: (22E, 24S)-stigmasta-5,22,25-trien-3 $\beta$-ol (1); 3',4',5,7-tetrahydroxyflavone (luteolin) (2); quercetin (3); kaempferol-7-O- $\beta$-D-glucoside (4); alphitolic acid (5); $\beta$-sitosteryl palmitate (6). The compounds (22E, 24S)-stigmasta-5,22,25-trien-3 $\beta$-ol (1); 3',4',5,7-tetrahydroxyflavone (luteolin) (2); kaempferol-7-O- $\beta$ - $D$-glucoside (4); alphitolic acid (5) and $\beta$-sitosteryl palmitate (6) were isolated from Albizia ferruginea for the first time. The structures of the isolated compounds were determined based on spectroscopic analysis and comparison of their spectral data with those in literature. The results of the antioxidant test revealed that at a dosage of $75 \mu \mathrm{g} / \mathrm{mL}$ the percentage weight of compound 3 was the highest, at dosages of 100 and $300 \mu \mathrm{g} / \mathrm{mL}$, compound 2 was highest and at dosage of $150 \mu \mathrm{g} / \mathrm{mL}$, compound $\mathbf{1}$ was the highest. The anti-radical activities of the compounds were significantly different $(\mathrm{p}<0.05)$ and is less than that compared to vitamin C. The result of the FRAP (ferric reducing antioxidant power) test showed that the roots are the part of the plant with the highest antioxidant capability.
\end{abstract}

\section{Introduction}

In many developing countries, access to conventional medicine remains limited to large cities. The difficulties of travel, shortage of qualified personnel, high cost of benefits and conventional medicines and socioeconomic factors, leave a large part of the population no other choices, than to resort to traditional medicine for common disease treatment [1]. Complementary and alternative medicine are commonly used to treat or prevent chronic diseases and to improve the quality of life. In Africa, more than $80 \%$ of the population uses traditional medicine and medicinal plants for their primary health care [2]. Some of these medicinal herbs have great potential and have been shown to be very beneficial in the treatment of wounds, promoting the healing rate of wounds with minimal pain, discomfort and scarring in the patients [3]. Faced with these problems, it is essential to find new effective and broad-spectrum substances that can fight against bacterial infections and attenuate or delay the oxidative process. One of the strategies for this research is to explore the plants used in traditional medicine. Many studies have shown that plants have antioxidant properties largely due to their phenolic compounds [4]. Phenolic compounds play an important role in human health because of their various pharmacological activities as anti-inflammatory, antiallergic, antimicrobial, antiviral, anticancer, cardioprotective and vasodilatory $[5,6]$. It is in this context, that in the framework of this study a species of the genus Albizia, widely used in the traditional pharmacopoeia to treat certain venereal diseases and for these antioxidant properties was studied [7]. The plants of the genus Albizia belong to the Fabaceae family and are widespread. This genus comprises about 120 species and is found in all tropical regions. Albizia ferruginea is a large deciduous tree up to $45-50 \mathrm{~m}$ tall; bole branchless up to 22 to $30 \mathrm{~m}$ tall, straight and cylindrical, up to 100 to $130 \mathrm{~cm}$ in diameter [8]. Albizia ferruginea is a medicinal plant widely used in Africa [9]. The bark is used in traditional medicine to treat dysentery, bronchial infections and pain caused by fever. In external 
2017. Identification was done by Mr. Nana, a botanist of the Cameroon National Herbarium, Yaounde where a plant specimen (voucher no. 49871/HNC) was deposited

\subsection{Extraction and Isolation}

The roots of Albizia ferruginea were dried, crushed and a (3.5 kg) powder was obtained. This powder was macerated in $20 \mathrm{~L}$ of $\mathrm{CH}_{2} \mathrm{Cl}_{2}-\mathrm{MeOH}$ (1:1) for $72 \mathrm{~h}$. The filtrate obtained was evaporated to dryness using a rotary evaporator under reduced pressure and (200 g) of crude extract were obtained. One hundred and fifty grams $(150 \mathrm{~g})$ of this crude extract was cold-fixed on (150 g) of silica gel $\left(\mathrm{SiO}_{2}\right)(0.063-0.200 \mathrm{~mm})$ and the buchner was loaded with (170 g) of silica as stationary phase to subjected flash chromatography. The column was eluted with a gradient of hexane, hexane/ethyl acetate, ethyl acetate, ethyl acetate/methanol then. After elution, 350 vials of about $400 \mathrm{~mL}$ each were collected. Three hundred and fifty 350 vials were pooled into 5 major fractions A (70 g), B (5 g), C (35 g), D (15 g), E (25 g) were collected, concentrated and grouped based on similar TLC profiles.

\subsection{Purification of the Different Fractions}

\subsubsection{Chromatography of Fraction $A$}

Fraction A (70 g) was fixed on (80 g) of silica gel and then column chromatography done with (100 g) of silica $(0.063-0.200 \mathrm{~mm})$ as stationary phase. Elution of this was done with hexane and hexane/ethyl acetate mixture by gradient of increasing polarity; We thus collected 150 vials grouped into 4 major fractions (A1, A2, A3, A4) per their TLC analysis.

Fraction A2 led to the isolation of (22E, 24S)-Stigmasta-5,22,25-trien$3 \beta$-ol (1) (15 mg) in the hexane/ethyl acetate system $20 \%$ and soluble in methylene chloride.

Fraction A3 led to the isolation of 3',4',5,7-tetrahydroxyflavone (luteolin) (2) (20 mg) in the hexane/ethyl acetate $30 \%$ system and soluble in methanol.

Fraction A4 led to the isolation of Quercetin (3) (10 mg) in pure ethyl acetate and soluble in methanol.

\subsubsection{Chromatography of Fraction $C$}

Chromatography of fraction $\mathbf{C}$ on a silica gel column using $\mathrm{CH}_{2} \mathrm{Cl}_{2}$ acetone (95:5) as eluent provided a fraction which was further purified by column chromatography with $\mathrm{CH}_{2} \mathrm{Cl}_{2}$-acetone (9:1) and then (4:1) to give Kaempferol-7-O- $\beta$-D-glucoside (4) (12 mg).

\subsubsection{Chromatography of Fraction $D$}

Fraction D was chromatographed on a column of silica gel, eluting with Hexane/ethyl acetate at increasing polarities. The fraction obtained with the mixture (65:35) was recrystallized from methylene chloride to give the alphitolic acid (5) (23 mg).

\subsubsection{Chromatography of Fraction $E$}

Fraction $\mathbf{E}$ was chromatographed on a column of silica gel eluting with $\mathrm{CH}_{2} \mathrm{Cl}_{2}$-AcOEt with increasing polarity. The fraction obtained with the mixture (95:5) was further purified by column chromatography using $\mathrm{CH}_{2} \mathrm{Cl}_{2}$-AcOEt as eluent and gave $\beta$-sitosteryl palmitate (6) (10 mg).

\subsection{Physical State and Spectral Data of Compounds (1-6)}

(22E, 24S) Stigmasta-5,22,25-trien-3 $\beta$-ol (1): (15 mg), Calculated mass of $\mathrm{C}_{29} \mathrm{H}_{46} \mathrm{O} ; \mathrm{m} / \mathrm{z}=410 \mathrm{~g} / \mathrm{mol}$. white needle; ${ }^{1} \mathrm{H}$ NMR $\left(600 \mathrm{MHz}, \mathrm{CDCl}_{3}\right): \mathrm{d}$ 0.68 (3H, s, H-18), 0.83 (3H, t, J = 7.6 Hz, H-23), 1.00 (3H,s, H-19), 1.01 (3H, d, $J=6.4 \mathrm{~Hz}, \mathrm{H}-21), 1.68$ (1H, s, H-27), $3.53(1 \mathrm{H}, \mathrm{m}, \mathrm{H}-3), 4.70(2 \mathrm{H}, \mathrm{bs}, \mathrm{H}-$ 26), $5.17(1 \mathrm{H}, \mathrm{dd}, J=15.6,7.2 \mathrm{~Hz}, \mathrm{H}-23), 5.24(1 \mathrm{H}, \mathrm{dd}, J=15.6,7.6 \mathrm{~Hz}, \mathrm{H}-$ 22), $5.34(1 \mathrm{H}, \mathrm{d}, J=5.6 \mathrm{~Hz}, \mathrm{H}-6)$.

${ }^{13} \mathrm{C} \mathrm{NMR}\left(\mathrm{CDCl}_{3}, 150 \mathrm{MHz}\right) \delta(\mathrm{ppm}) 37.24$ (C-l), 148.60 (C-25) 140.74 (C5), 137.18 (C-22), 130.02 (C-23), 121.67 (C-6), 109.50(C-26), $71.79(\mathrm{C}-3)$. 56.83 (C-14). 55.87(C-17). 51.98 (C-24), 50.14 (C-9), 42.49 (C-13), 42.24 (C-4), 40.17 (C-20), 39.66 (C-12), 36.49 (C-10), 31.86 (C-7, 8). 31.65 (C-2). $28.68(\mathrm{C}-16)$

3',4',5,7-tetrahydroxyflavone (luteolin) (2): (20 mg), yellow amorphous powder; m.p. $325^{\circ} \mathrm{C}$; $\mathrm{R}_{\mathrm{f}}$ value of 0.74 in solvent system IV; UV $\lambda \max (\mathrm{MeOH}) 254,349,(\mathrm{MeOH}+\mathrm{NaOM}) 266,401,\left(\mathrm{MeOH}+\mathrm{AlCl}_{3}\right) 273$, 421, $\left(\mathrm{MeOH}+\mathrm{AlCl}_{3}+\mathrm{HCl}\right) 274,355,(\mathrm{MeOH}+\mathrm{NaOAc}) 269$, 393( $\left.\mathrm{MeOH}+\mathrm{NaOAc}+\mathrm{H}_{3} \mathrm{BO}_{3}\right)$ 264, 376; IR Vmax (KBr) cm-1: $3420(\mathrm{O}-\mathrm{H})$, 2943 and 2859(C-H), 1609 (C=0), 1509 (C=C), 1261, 1168, 1120 (C-O), 830, 755, 688; EI-MS $m / z: 286\left[\mathrm{M}^{+}, 82.3\right], 258,228,153,135,134,96$;

The ${ }^{1} \mathrm{H}$ NMR ( $\left.\mathrm{CD}_{3} \mathrm{OD}, 500 \mathrm{MHz}\right): \delta \mathrm{H} 6.52(1 \mathrm{H}, \mathrm{s}, \mathrm{H}-3), 6.18(1 \mathrm{H}, \mathrm{d}, J=1.75$ Hz, H-6), 6.42(1H, d, J=1.75 Hz, H-8), $7.36\left(1 \mathrm{H}, \mathrm{d}, J=2 \mathrm{~Hz}, \mathrm{H}-2^{\prime}\right), 6.98(1 \mathrm{H}$, $\left.\mathrm{d}, J=8.6 \mathrm{~Hz}, \mathrm{H}-5{ }^{\prime}\right)$ and $7.34\left(1 \mathrm{H}, \mathrm{dd}, J=2,8.6 \mathrm{~Hz}, \mathrm{H}-6{ }^{\prime}\right)$.

https://doi.org/10.30799/jacs.212.19050301
${ }^{13} \mathrm{C}$ NMR (CD $\left.{ }_{3} \mathrm{OD}, 125 \mathrm{MHz}\right): \delta \mathrm{C} 160.0$ (C-2), 103.1 (C-3), 182.5 (C-4) 158.1 (C-5), 101.9 (C-6), 165.0 (C-7), 101.8 (C-8), 164.7 (C-9), 103.0 (C10), $118.5\left(\mathrm{C}-1^{`}\right), 112.4\left(\mathrm{C}-2^{\prime}\right), 145.7\left(\mathrm{C}-3^{\prime}\right), 149.6$ (C-4'), $115.9\left(\mathrm{C}-5^{\prime}\right)$ and $122.3\left(\mathrm{C}-6{ }^{\prime}\right)$.

Quercetin (3): (10 mg), Yellow needles. $\mathrm{R}_{\mathrm{f}} 0.54\left(\mathrm{CH}_{2} \mathrm{Cl}_{2}-\left(\mathrm{CH}_{3}\right)_{2} \mathrm{CO} 2: 1\right)$ ESI-MS: $\mathrm{m} / \mathrm{z} 302.9[\mathrm{M}+\mathrm{H}]^{+}$(positive mode), m/z $301.0[\mathrm{M}-\mathrm{H}]^{-}$(negative mode). ${ }^{1} \mathrm{H}-\mathrm{NMR}\left(\mathrm{CD}_{3} \mathrm{OD}\right): \delta 6.2(1 \mathrm{H}, \mathrm{d}, J=2.0 \mathrm{~Hz}, \mathrm{H}-8), 6.4(1 \mathrm{H}, \mathrm{d}, J=2.0 \mathrm{~Hz}$, $\mathrm{H}-6), 6.90\left(1 \mathrm{H}, \mathrm{d}, J=8.5 \mathrm{~Hz}, \mathrm{H}-5^{\prime}\right), 7.64\left(1 \mathrm{H}, \mathrm{dd}, J=8.5 \mathrm{~Hz}, 2.5 \mathrm{~Hz}, \mathrm{H}-6^{\prime}\right)$, $7.75\left(1 \mathrm{H}, \mathrm{d}, J=2.5 \mathrm{~Hz}, \mathrm{H}-2^{\prime}\right)$

${ }^{13} \mathrm{C}-\mathrm{NMR}\left(\mathrm{CD}_{3} \mathrm{OD}\right): \delta 94.4$ (d, C-8), 99.2 (d, C-6), 104.5 (s, C-10), 116.0 (d, C-2'), $116.2\left(\mathrm{~d}, \mathrm{C}-5^{\prime}\right), 121.7\left(\mathrm{~s}, \mathrm{C}-6^{\prime}\right), 124.1\left(\mathrm{~s}, \mathrm{C}-1^{\prime}\right), 137.2(\mathrm{~s}, \mathrm{C}-3), 146.2$ (s, C-3'), 148.0 (s, C-2), 148.7 (s, C-4'), 158.2 (s, C-9), 162.5 (s, C-5), 165.5 (s, C7), $177.3(\mathrm{~s}, \mathrm{C}-4)$.

Kaempferol-7- $O-\beta$ - $D$-glucoside (4) (12 mg): ${ }^{1} \mathrm{H}$ NMR (Pyridine- $\left.\mathrm{d}_{5}\right): \delta$ $5.73\left(1 \mathrm{H}, \mathrm{d}, \mathrm{J}=6.5\right.$, anomeric protons of glucose, $\left.\mathrm{H}-1^{\prime \prime}\right), 3.87-4.60(6 \mathrm{H}, \mathrm{m}$, protons of sugar party), $6.69(1 \mathrm{H}, \mathrm{d}, J=2.5, \mathrm{H}-6), 6.91(1 \mathrm{H}, \mathrm{d}, J=2.5, \mathrm{H}-8)$, $7.25\left(1 \mathrm{H}, \mathrm{d}, J=8.5, \mathrm{H}-5^{\prime}\right), 7.96\left(1 \mathrm{H}, \mathrm{dd}, J=2.5\right.$ and $\left.8.5, \mathrm{H}-6^{\prime}\right), 8.50(1 \mathrm{H}, \mathrm{d}, J$ $\left.=2.5, \mathrm{H}-2^{\prime}\right)$.

${ }^{13} \mathrm{C}$ NMR (150 MHz; DMSO-d 6 ): $\delta$ 147,5 (C-2), 136,2 (C-3), 176,5 (C-4), 160.3 (C- 5), 98.9 (C-6), 162.4 (C-7), 94.5 (C-8), 155.9 (C-9), 104.3 (C-10), $121.2\left(\mathrm{C}-1^{\prime}\right), 129.8\left(\mathrm{C}-2^{\prime}\right), 115.5\left(\mathrm{C}-3^{\prime}\right), 159.4\left(\mathrm{C}-4^{\prime}\right), 115.5\left(\mathrm{C}-5^{\prime}\right), 129.7(\mathrm{C}-$ $\left.6^{\prime}\right), 99.8\left(\mathrm{C}-1^{\prime \prime}\right), 73.4\left(\mathrm{C}-2^{\prime \prime}\right), 77.3\left(\mathrm{C}-3^{\prime \prime}\right), 69.7\left(\mathrm{C}-4^{\prime \prime}\right), 76.5\left(\mathrm{C}-5^{\prime \prime}\right), 60.8(\mathrm{C}-$ $\left.6^{\prime \prime}\right)$.

Alphitolic acid (5) : (23 mg), White powder ; Formula: $\mathrm{C}_{30} \mathrm{H}_{48} \mathrm{O}_{4}$; calculated mass : $\mathrm{m} / \mathrm{z}=472:{ }^{1} \mathrm{H}$ NMR $(600 \mathrm{MHz}$; DMSO-d 6$) \delta 3.61(1 \mathrm{H}$ ddd,H-2), 2.89 (1H,d, J=9.3, H-3), 3.27 (1H,ddd, J=2.27, H-13), 1.46 (1H,t, $J=11.3, \mathrm{H}-18), 2.96$ (1H,m,H-19), 1.01 (3H,s,H-23), 0.92 (3H,s,H-24), 0.97 (3H,s,H-25), 0.99 (3H,s,H-26), 4.71 (1H,d, J=1.8,H-29 $), 1.70$ (3H,s,H-30),

${ }^{13} \mathrm{C}-\mathrm{NMR}(150 \mathrm{MHz}$; DMSO-d 6 ) $\delta 48.60(\mathrm{C}-1), 69.90$ (C-2), $84.50(\mathrm{C}-3)$, 39.56 (C-4), 56.93 (C- 5), 19.62 (C-6), 35.56 (C-7), 42.11 (C-8), 52.10 (C-9) 39.77 (C-10), 22.35 (C-11), 26.97 (C-12), 39.62 (C-13), 43.77 (C-14), 31.92 (C-15), 33.49 (C-16), 57.64 (C-17), 50.57 (C-18), 48.53 (C-19), 152.08 (C20), 30.89 (C-21), 38.24 (C-22), 29.24 (C-23), 17.34 (C-24), 17.99 (C-25), 16.74 (C- 26), 15.18 (C-27), 180.16 (C-28), 110.30 (C-29), 19.64 (C-30).

$\beta$-sitosteryl palmitate (6): Calculated mass of $\mathrm{C}_{45} \mathrm{H}_{78} \mathrm{O}_{2}, \mathrm{~m} / \mathrm{z}=651 \mathrm{~g} / \mathrm{mol}$

${ }^{1} \mathrm{H}$ NMR (600 MHz, $\left.\mathrm{CDCl}_{3}\right) \delta(\mathrm{ppm}): 11.1(2 \mathrm{H}, \mathrm{m}) ; 1.53(2 \mathrm{H}, \mathrm{m}) ; 3.53$ $(1 \mathrm{H}, \mathrm{m}) ; 2.32(2 \mathrm{H}, \mathrm{d}) ; 5.39(1 \mathrm{H}, \mathrm{m}) ; 2.38(1 \mathrm{H}, \mathrm{m}) ; 1.53(2 \mathrm{H}, \mathrm{m}) ; 2.02(2 \mathrm{H}$, $\mathrm{m}) ; 0.84(2 \mathrm{H}, \mathrm{m}) ; 1.09(1 \mathrm{H}, \mathrm{m}) ; 1.12(1 \mathrm{H}, \mathrm{m}) ; 0.68(3 \mathrm{H}, \mathrm{s}) ; 1.01(3 \mathrm{H}, \mathrm{s}) ; 0.96$ $(3 \mathrm{H}, \mathrm{d}) ; 5.18(1 \mathrm{H}, \mathrm{m}) ; 5.06(1 \mathrm{H}, \mathrm{m}) ; 0.95(1 \mathrm{H}, \mathrm{m}) ; 1.70(1 \mathrm{H}, \mathrm{m}) ; 0.88(3 \mathrm{H}$ $\mathrm{m}) ; 0.86(3 \mathrm{H}, \mathrm{m}) ; 0.84(3 \mathrm{H}, \mathrm{m}) ; 0.86(3 \mathrm{H}, \mathrm{m}) ; 2.30(2 \mathrm{H}, \mathrm{t}) ; 1.19(2 \mathrm{H}, \mathrm{m}) ; 1.25$ $-1.29(20 \mathrm{H}, \mathrm{m}) ; 0.92(3 \mathrm{H}, \mathrm{t})$.

${ }^{13} \mathrm{C}$ NMR (150 MHz, $\left.\mathrm{CDCl}_{3}\right) \delta(\mathrm{ppm}): 11.88 ; 12.00 ; 14.14 ; 18.9 ; 19.05$; $19.1 ; 19.42 ; 19.85 ; 21.10 ; 21.2 ; 22.72 ; 23.08 ; 24.32 ; 24.74 ; 25.5 ; 26.08$; 28.27 ; 29.09; 29.16; 29.27-29.73; 31.65; 31.8; 31.92; 31.92; 33.83; 33.85; $33.96 ; 33.96 ; 36.17 ; 36.52 ; 37.27 ; 39.79 ; 39.9 ; 40.52 ; 42.29 ; 42.34 ; 45.85$; $50.15 ; 51.26$; $55.97 ; 56.07$; $56.78 ; 57.0 ; 71.85 ; 121.76 ; 129.29 ; 138.34$; $140.76 ; 178.38$.

\subsection{Method of Evaluating Antioxidant Power}

The antioxidant activity of the compounds will be determined qualitatively and quantitatively by DPPH and FRAP (Ferric Reducing Antioxidant Power) methods. The DPPH method is based on the ability of an antioxidant in reducing 2,2-diphenyl-1-picrylhydrazil (DPPH) to a yellow compound diphenyl picryl-hydrazine.

\subsubsection{Quantitative Test of the Reduction of Free Radical DPPH}

\subsubsection{Principle}

The effect of the compounds on the stable DPPH• was determined by the Molyneux method (Fig. 1) [11]. The method is based on the degradation of the DPPH$\cdot$. In the presence of an antioxidant capable of yielding a single electron, the purple DPPH ${ }^{\circ}$ synthetic radical will be stabilized in DPPH and thus discoloration of the solution will occur. The decolorization of the radical measured by spectrophotometry at $517 \mathrm{~nm}$ is proportional to the concentration of antioxidant [11].
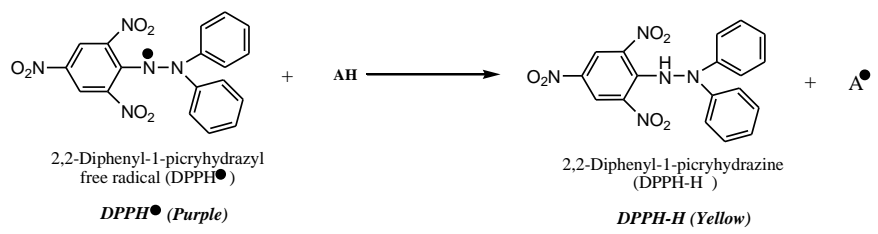

Fig. 1 DPPH• Free radical conversion DPPH-H by antioxidant compounds

\subsubsection{Method}

In various test tubes, we introduced $3000 \mu \mathrm{L}$ of a range of test compounds $(75 \mu \mathrm{g} / \mathrm{mL}, 100 \mu \mathrm{g} / \mathrm{mL}, 150 \mu \mathrm{g} / \mathrm{mL}$ and $300 \mu \mathrm{g} / \mathrm{mL}$ ) followed 
by $1000 \mu \mathrm{L}$ of the $\mathrm{DPPH} \cdot$ methanol solution $(0.1 \mathrm{mM})$. After vortexing, the mixture was left in the dark for $30 \mathrm{~min}$ and the optical density was measured at $517 \mathrm{~nm}$. The negative control was prepared solely based on the compound-free DPPH solution and the positive control being represented by the standard antioxidant solution (vitamin C) whose absorbance was measured under the same conditions as the test sample. The antioxidant activity is estimated as a percentage inhibition or percentage of antioxidant activity, according to the following formula,

$\%$ Inhibition of the radical DPPH $=\frac{(\text { Abs DPPH }- \text { Abs Compounds })}{\text { Abs DPPH }} \times 100$

where Abs DPPH is the absorbance of the hydroethanol solution of DPPH and Abs compounds, compound at the wavelength of $517 \mathrm{~nm}$. The $\mathrm{IC}_{50}$ values (concentration of compounds required to trap 50\% of the free radicals) were then calculated from the regression equations obtained for different concentrations of the different compounds. Table 1 shows the procedure for the determination of the free radical potential by the DPPH method.

Table 1 Procedure for determining the anti-radical potential using the DPPH method

\begin{tabular}{lllllll}
\hline \multirow{2}{*}{ Reactants $(\mathrm{mL})$} & \multicolumn{6}{c}{ Concentration of test solutions or standard $(\mu \mathrm{g} / \mathrm{mL})$} \\
\cline { 2 - 7 } & 0 & 25 & 75 & 100 & 150 & 300 \\
\hline Compounds or ascorbic acid & - & 3 & 3 & 3 & 3 & 3 \\
Distilled water & 3 & - & - & - & - & - \\
DPPH $(0.1 \mathrm{mM})$ Reagent & 1 & 1 & 1 & 1 & 1 & 1 \\
Homogenisation and incubation for 30 & minutes (in the dark and at ambient
\end{tabular}

Homogenisation and incubation for 30 minutes (in the dark and at ambient temperature); Optical density reading at $517 \mathrm{~nm}$ against control

\subsubsection{Determination of Antioxidant Potential by Ferric Reducing Antioxidant}

\section{Power (FRAP)}

2.6.2.1 Principle

FRAP was determined according to the method of Benzie and Strain [12]. This method measures the ability of the samples to reduce iron, in ferric form $\left(\mathrm{Fe}^{3+}\right)$ to the ferrous form $\left(\mathrm{Fe}^{2+}\right)$ to a low $\mathrm{pH}(3.6)$. An intense blue color is formed when the ferric tripyridyltriazine (TPTZ) complex is reduced to ferrous tripyridyltriazine and the absorbance is measured at $593 \mathrm{~nm}$, the higher the absorbance, the higher the reduction power [12].

\subsubsection{Method}

In test tubes containing $75 \mu \mathrm{L}$ of sample solution $(100 \mu \mathrm{g} / \mathrm{mL}) 1000 \mu \mathrm{L}$ of FRAP reagent was added. Absorbance was then read spectrophotometer at $593 \mathrm{~nm}$ after $12 \mathrm{~min}$ incubation. We have prepared under the same conditions a control with distilled water in place of the solution of the compounds. The quantification was carried out according to a standard range established under the same conditions with ascorbic acid ( 0 to $80 \mu \mathrm{g} / \mathrm{mL}$ ). The results will be expressed in equivalent $\mathrm{mg}$ of ascorbic acid/g of dry matter. Table 2 shows the procedure for determining the antioxidant potential of the compounds by the FRAP method.

Table 2 Antioxidant potential of the compounds by the FRAP Method

\begin{tabular}{|c|c|c|c|c|c|c|c|c|}
\hline \multirow{2}{*}{ Reagents $(\mu \mathrm{L})$} & \multicolumn{6}{|c|}{ Standard concentration $(\mu \mathrm{g} / \mathrm{mL})$} & \multirow[t]{2}{*}{ Control } & \multirow[t]{2}{*}{ Test } \\
\hline & 0 & 10 & 20 & 40 & 60 & 80 & & \\
\hline Ascorbic acid $100 \mu \mathrm{g} / \mathrm{ml}$ & L- & 7.5 & 15 & 30 & 45 & 60 & & \\
\hline Distilled water & 75 & 67.5 & 60 & 45 & 30 & 15 & 75 & \\
\hline Compound $100 \mu \mathrm{g} / \mathrm{mL}$ & - & - & - & - & - & - & - & 75 \\
\hline FRAP Reagent & 1000 & 1000 & 1000 & 1000 & 1000 & 1000 & 1000 & 1000 \\
\hline
\end{tabular}

Ascorbic acid was used as a positive control and the results were expressed in equivalent mg of ascorbic acid per gram dry matter (mg $\mathrm{AAE} / \mathrm{g}$ MS) using the following regression equation: $\mathrm{y}=0.0019 \mathrm{x}$ $\left(\mathrm{R}^{2}=0.925\right)$.

\section{Results and Discussion}

The roots of Albizia ferruginea were cut, dried and crushed; ( $3.5 \mathrm{~kg}$ ) of powder thus obtained were macerated in $20 \mathrm{~L}$ of $\mathrm{CH}_{2} \mathrm{Cl}_{2}-\mathrm{MeOH}$ 1:1 for 72 hours. The filtrate was concentrated on a rotary evaporator, which made it possible to obtain $200 \mathrm{~g}$ of crude extract. This extract was subjected to a Phytochemical Screening and fractionation to evaluate the antioxidant activities, then to isolate the secondary metabolites found in these fractions.

\subsection{Elucidation of Structures of Isolated Compounds}

Extracts of Albizia ferruginea were fractionated by silica gel column chromatography to give six compounds (1-6) (Fig. 2).

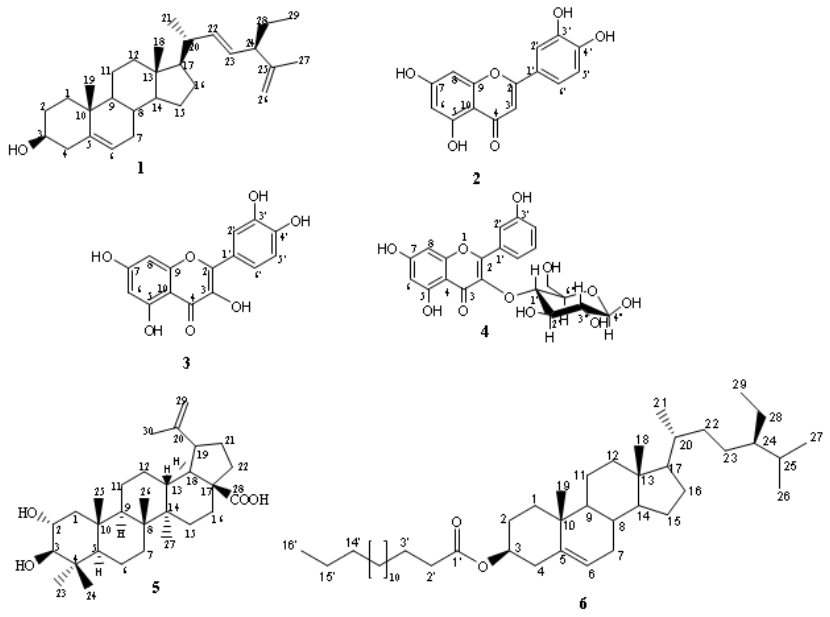

Fig. 2 Structure of compounds 1 to 6 isolated from Albizia ferruginea

The compound (1) was obtained in the form of white powder sheet in the hexane ethyl acetate $20 \%$ system, it is soluble in ethyl acetate and crystallized in methanol. Its molecular formula is $\mathrm{C}_{29} \mathrm{H}_{46} \mathrm{O}$ and its calculated mass is $\mathrm{m} / \mathrm{z}=410$. Its ${ }^{1} \mathrm{H}$ NMR spectrum shows in the weak fields: A broad multiplet at $\delta_{\mathrm{H}}=3.52 \mathrm{ppm}$ attributable to the proton carried by a hydroxylated carbon, $\mathrm{A}$ broad doublet of an ethylene proton at $\delta_{\mathrm{H}}=$ $5.35 \mathrm{ppm}$ and two doublets doubled at $\delta_{\mathrm{H}}=5.24 ; 5.17 \mathrm{ppm}$. Signals at $\delta_{\mathrm{H}}$ $3.52 ; 5.35 ; 5.24$ and 5.17 attributable to protons $\mathrm{H}_{3}, \mathrm{H}_{6}, \mathrm{H}_{22}$ and $\mathrm{H}_{23}$. Signals of three singlet characteristic of angular methyls at $\delta_{\mathrm{H}}=0.69 \mathrm{ppm}\left(\mathrm{H}_{18}\right)$; $1.01 \mathrm{ppm}\left(\mathrm{H}_{19}\right) ; 1.65 \mathrm{ppm}\left(\mathrm{H}_{27}\right)$. Finally, a triplet at $\delta_{\mathrm{H}}=0.83 \mathrm{ppm}$ attributable to $\mathrm{H}_{29}$. These data clearly show that (1) has a stigmasterol-like backbone [13]. The ${ }^{13} \mathrm{C}$ NMR spectrum, completely decoupled, reveals the presence of 29 carbon signals, among which: Six ethylenic carbons at $\delta \mathrm{C}=$ $140.90 \mathrm{ppm} ; 121.84 \mathrm{ppm} ; 137.35 \mathrm{ppm} ; 130.17 \mathrm{ppm} ; 148.78 \mathrm{ppm}$ and 109.66 ppm attributable respectively to $\mathrm{C}_{5}, \mathrm{C}_{6}, \mathrm{C}_{22}, \mathrm{C}_{23}, \mathrm{C}_{25}$ and $\mathrm{C}_{26}$. A signal characteristic of a hydroxylated carbon at $\delta_{\mathrm{C}}=71.96 \mathrm{ppm}$ attributable to $\mathrm{C}_{3}$. To finish a set of carbon $\mathrm{sp}^{3}$ at $\delta_{\mathrm{C}}$ between 56.99 to $12.21 \mathrm{ppm}$. On the basis of these data and in comparison, with the data of the literature, the compound (1) has been given the following name (22E, 24S)-Stigmasta5,22,25-trien-3 $\beta$-ol $[14,15]$, isolated from Albizia ferruginea for the first time.

The IR spectrum of the compound (2) showed a hydroxyl absorption band at $3420 \mathrm{~cm}^{-1}$ and a carbonyl group band at $1609 \mathrm{~cm}^{-1}$. Compound 2 was recognized as a Flavone compound based on its UV absorption maxima at $349 \mathrm{~nm}$ (band I) and $254 \mathrm{~nm}$ (band II) [16]. The EI-MS spectrum had a molecular ion at $\mathrm{m} / \mathrm{z}=286\left[\mathrm{M}^{+}\right]$with fragments at $\mathrm{m} / \mathrm{z} 258\left[\mathrm{M}^{+}-\mathrm{CO}\right]$, 153 [benzoyl portion of ring A] and 135 [for cinnamoyl of ring B]. Its ${ }^{1} \mathrm{H}$ NMR spectrum showed the signals of the ABX ring B spin system at $\delta \mathrm{H} 7.36$ $(1 \mathrm{H}, \mathrm{d}, \mathrm{J}=2 \mathrm{~Hz}), 7.34(1 \mathrm{H}, \mathrm{dd}, \mathrm{J}=, 8.6 .2 \mathrm{~Hz})$. and $6.98(1 \mathrm{H}, \mathrm{d}, \mathrm{J}=8.6 \mathrm{~Hz})$ for $\mathrm{H}-2$ ', H-6' and H-5, respectively. He also showed a singlet signal at $\delta \mathrm{H} 6.52$ for $\mathrm{H}-3$. Two protons were at $\delta \mathrm{H} 6.42(1 \mathrm{H}, \mathrm{d}, \mathrm{J}=1.7 \mathrm{~Hz})$ and $6.18(1 \mathrm{H}, \mathrm{d}, \mathrm{J}$ $=1.7 \mathrm{~Hz}$ ) for $\mathrm{H}-8$ and $\mathrm{H}-6$, respectively. On its ${ }^{13} \mathrm{C}$ spectrum, the carbonyl signal is observed at $\delta$ C 182.7 (C-4) and the signal C-3 at $\delta$ C 103.1. Oxygen containing the carbons showed downward signals at $\delta \mathrm{C} 165.0(\mathrm{C}-7), 164.7$ (C-9), 160.0 (C-2), 158.1 (C-5), 149.6 (C-4) and 145.7 (C-3') for carbon atoms carrying oxygen. By comparing the UV, IR, MS, and ${ }^{1} \mathrm{H}$ and ${ }^{13} \mathrm{C}$ NMR spectra of compound $\mathbf{2}$ in the literature [16], compound $\mathbf{2}$ was identified as 3',4',5,7-tetrahydroxyflavone (luteolin), already isolated from Albizia lebbeck [17], but isolated for the first time from Albizia ferruginea.

The compound (3) is obtained with pure acetate and is soluble in methanol. On its IR spectrum, we observe the vibration bands at 3314 $[\mathrm{OH}], 2905[\mathrm{C}-\mathrm{H}], 1732$ [C=0], 1657 [C=C], 1612, 1567, 1505, 1459, 1380 and $1230 \mathrm{~cm}^{-1} .{ }^{1} \mathrm{H} \mathrm{NMR} \mathrm{CD}{ }_{3} \mathrm{OD}(5 \mathrm{ppm}): \delta 6.17(1 \mathrm{H}, \mathrm{d}, \mathrm{J}=1.8 \mathrm{~Hz}, \mathrm{H}-6), 6.38$ $(1 \mathrm{H}, \mathrm{d}, \mathrm{J}=1.8 \mathrm{~Hz}, \mathrm{H}-8) ; \delta \mathrm{H} 6.89\left(2 \mathrm{H}, \mathrm{d}, \mathrm{J}=9.2 \mathrm{~Hz}, \mathrm{H}-2^{\prime}, 6^{\prime}\right) ; \delta \mathrm{H} 8.08(2 \mathrm{H}, \mathrm{d}$, $\left.\mathrm{J}=8.8 \mathrm{~Hz}, \mathrm{H}-3^{\prime}, 5^{\prime}\right) .{ }^{13} \mathrm{C}$ NMR (CD $\left.{ }_{3} \mathrm{OD}\right): \delta \mathrm{H} 94.4(\mathrm{C}-8), 99.3(\mathrm{C}-6), 104.5(\mathrm{C}-$ 10), 116.3 (C-3 ', 5'), 123.7 (C-1 '), 130.7 (C-2', 6 '), 137.2 (C-3), 148.0 (C9), 158.2 (C-2), 160.6 (C-1'), (C-5), 162.5 (C-7), 165.6 (C-4 ') and 177.4 (C4). On its ${ }^{1} \mathrm{H}$ NMR spectrum, 5 aromatic signals are observed. The aromatic proton doublets at 6.25 and $6.50 \mathrm{ppm}(\mathrm{J}=1.8 \mathrm{~Hz})$ were due to the protons meta-coupling of a 5.7-substituted ring A for the H-6 and H-8 protons. Respectively, while the signals at $\delta 6.98(\mathrm{~d}, \mathrm{~J}=8.4 \mathrm{~Hz}, 1 \mathrm{H})$, at $7.66(\mathrm{dd}, \mathrm{J}=$ $1.8,8.4 \mathrm{~Hz}, 1 \mathrm{H})$ and at $7.79(\mathrm{~d}, \mathrm{~J}=1.8 \mathrm{~Hz}, 1 \mathrm{H})$ were assigned to the $\mathrm{H}-5^{\prime}, \mathrm{H}-$ 6' and H-2'protons, showing an ABX coupling system of a 3', 4'-substituted 
B-ring. a Flavanol. On the basis of these data and in comparison, with literature data, compound 3 has been identified with quercetin (3) [1820].

Compound 4 showed a peak at $\mathrm{m} / \mathrm{z}=487.0844$ in HR ESI-MS, corresponding to a molecular formula of $\mathrm{C}_{21} \mathrm{H}_{20} \mathrm{O}_{12} \mathrm{Na}$, corroborated by ${ }^{13} \mathrm{C}$ NMR data. The APCI-MS spectrum of 4 showed peaks at $\mathrm{m} / \mathrm{z}=301$ (loss of 162 ), suggesting the presence of a hexose linked to an aglycone moiety. The configuration of the sugar moiety was determined to be the basis of the anomeric proton coupling constant $(J 100,200=7.6 \mathrm{~Hz})$. In addition, the anomeric proton had a correlation in the HMBC spectrum with $\delta \mathrm{C}$ 163.7 (C-7). These physical and spectroscopic data compared to those described in the literature have identified compound 4 as Kaempferol-70 - $\beta$-D-glucoside (4) [21,22], isolated from Albizia ferruginea for the first time.

Compound (5) was obtained as a white powder in the hexane/ethyl acetate 35\% system. It is soluble in methanol and gives a purplish pink coloration to the Liebermann Burchard test characteristic of triterpenes. Its ${ }^{1} \mathrm{H}$ NMR spectrum $(600 \mathrm{MHz}, \mathrm{MeOD})$ shows: Five singlet resonant at $\delta \mathrm{H}$ $0.78,0.92,0.97,0.99$ and $1.01 \mathrm{ppm}$ attributable to the angular methyls of the pentacyclic triterpenes and a sixth methyl group deshielded to 1.70 ppm indicating an electronic environment different from the other 05 . Resonances of isopropenyl protons are also observed at $\delta \mathrm{H} 4.71(\mathrm{~d}, \mathrm{~J}=2.0$ $\mathrm{Hz})$ and $4.60 \mathrm{ppm}(\mathrm{dd}, \mathrm{J}=2.0-1.4 \mathrm{~Hz})$ and a methyl $(\delta \mathrm{H} \mathrm{1.70})$ suggesting a lupane or hopane skeleton. It also has a resonant doublet at $2.89 \mathrm{ppm}(\mathrm{J}=$ $9.6 \mathrm{~Hz}$ ) attributable to the proton $\mathrm{H}-3$. On the COZY spectrum, the $\mathrm{H}-3$ proton correlates with the unshielded $\mathrm{H}-2$ proton $(\delta \mathrm{H} 3.61$, ddd, $\mathrm{J}=11.3$ 9.6-4.6 Hz). The chemical shift of carbon $C-2(\delta C 70.0)$ confirms the presence of a hydroxyl group in position 2 .

The ${ }^{13} \mathrm{C}$ APT NMR spectrum of compound 5 reveals the presence of 30 carbons from which we can distinguish the following characteristic carbons: A signal resonant at $\delta \mathrm{C} 180.1 \mathrm{ppm}$ indicating the presence of a free carboxyl function in the molecule. HMBC correlations between this carbon and protons $\mathrm{H}-16, \mathrm{H}-18$, suggest that the carbonyl is placed in position 28. A carbon mass between $14-50 \mathrm{ppm}$ attributable to $\mathrm{CH}_{2}, \mathrm{CH}$ and $C$ quaternary. Two oxygenated carbons at 84.7 and $70.0 \mathrm{ppm}$. The two ethylenic carbons detected, including a quaternary carbon located at 152.2 and a methylene carbon at $110.5 \mathrm{ppm}$. By means of the analysis of the direct hetero-nuclear correlations ${ }^{1} \mathrm{~J} \mathrm{H}-\mathrm{C}$ observed on the J-modulated HSQC spectrum of 5 combined with the ${ }^{13} \mathrm{C}$ APT spectrum, we can count 7 quaternary carbons, 7 methines, 10 methylenes and 6 methyls for the compound 5. A from the protons identified on the COZY spectrum, the corresponding carbons $\mathrm{C}-1(\delta \mathrm{C} 48.6), \mathrm{C}-2(\delta \mathrm{C} 69.9)$ and $\mathrm{C}-3(\delta \mathrm{C} 84.5)$ of ring $A, C-11$ are assigned, $C-12(\delta C 25.4)$ and $C-13(\delta C 39.62)$ of ring $C, C-$ $18(\delta \mathrm{C} 50.57$ ), $\mathrm{C}-19(\delta \mathrm{C} 48.53), \mathrm{C}-21(\delta \mathrm{C} 30.5)$ and $\mathrm{C}-22(\delta \mathrm{C} 37.1)$ of ring E. This analysis also makes it possible to identify the degree of substitution of the double bond deduced by the fact that the two ethylenic protons are carried by the same carbon (110.5 ppm) which confirms the presence of an isopropenyl exo-cyclic double bond $\left(\Delta^{20}\right)$. The correlations observed between the proton $\mathrm{H}-18(\delta \mathrm{H} 1.66)$ and the carbons $\mathrm{C}-13, \mathrm{C}-14, \mathrm{C}-17$, the quaternary carbon of the isopropenyl group $(\delta C 150.2)$ and the carboxyl at $181.2 \mathrm{ppm}$ allow to place unambiguously the isopropenyl group in position C-19 and the carbonyl in position 28 as in the lupane skeleton. The axial orientation of proton $\mathrm{H}-3$ and axial proton $\mathrm{H}-2$ is established from the values of the coupling constant between $\mathrm{H}-2$ and $\mathrm{H}-3$ protons greater than $9 \mathrm{~Hz}$. The combination of all these physical and spectroscopic data compared to those described in the literature made it possible to identify the compound 5 to Alphitolic Acid [23,24].

Compound (6) was obtained in the form of a white powder soluble in ethyl acetate. The analysis of its ${ }^{1} \mathrm{H}$ NMR spectrum shows in the weak fields a broad triplet integrating $1 \mathrm{H}$ at 5.35 ppm, two doublets of low intensity, one at 5.18 and the other at $5.06 \mathrm{ppm}$ integrating for $1 \mathrm{H}$. Each and a multiplet integrating $1 \mathrm{H}$ at $3.53 \mathrm{ppm}$. In strong fields, there is a large and intense peak between 1.25 and 1.29 ppm, integrating $20 \mathrm{H}$ and a peak characteristic of a terminal methyl at $0.91 \mathrm{ppm}$ integrating $3 \mathrm{H}$. On its ${ }^{13} \mathrm{C}$ NMR spectrum, olefinic carbons are observed at $\delta_{C} 140.76 ; 121.76 ; 138.34$ and $129.29 \mathrm{ppm}$, an oxygenated carbon at $\delta_{C} 71.85 \mathrm{ppm}$, a $178.38 \mathrm{ppm}$ signal characterizing a carbonyl group, a broad and intense peak between 29.27 and $29.73 \mathrm{ppm}$ and a signal, $14.14 \mathrm{ppm}$. The peaks observed at $\delta_{H}$ $5.18(1 \mathrm{H}, \mathrm{m})$ and at $\delta_{H} 5.06(1 \mathrm{H}, \mathrm{m})$ are attributable respectively to the signals of the H-22 and H-23 protons of stigmasterol and to a triplet at $\delta_{H}$ 5.35 integrating $1 \mathrm{H}$. Characteristic of the vinylic proton $\mathrm{H}-6$ of phytosterols, in this case stigmasterol. This is confirmed on the HSQC spectrum by signals at $\delta_{C} 121.76$ (C-6) and 140.76 (C-5) ppm. Similarly, on the ${ }^{1} \mathrm{H}$ NMR spectrum, the multiplet appearing at $\delta_{H} 3.53(1 \mathrm{H})$ corresponding to a proton carried by an oxygenated carbon (C-3), characteristic of the H-3 proton steroid derivatives. In addition, the peak observed at $\delta_{C} 178.38 \mathrm{ppm}$ is attributable to the C-1' carbon which characterizes the carbonyl group bonded to the oxygen at position 3 of the sterol. The presence of a linear chain is explained by the presence of a peak https://doi.org/10.30799/jacs.212.19050301 set between 29.27 and 29.73 ppm attributable to C-4' to C-13' carbons and a terminal methyl group [25]. The analysis of its HSQC spectrum allows for the attribution of some carbon protons. Thus, in strong fields, between $\delta_{H}$ 0.67 and $\delta_{H} 1.02 \mathrm{ppm}$, there are several methyl groups that can be observed at $\delta_{H} 0.68$ (3H, s, Me-18); $0.84(3 \mathrm{H}, \mathrm{s}, \mathrm{Me}-29) ; 0.88(3 \mathrm{H}, \mathrm{d}, \mathrm{Me}-$ 26); 0.86 (3H, s, Me-27); 1.01 (3H, s, Me-19); 0.96 (3H, s, Me-21). On its HMBC spectrum, the correlation between the proton $\mathrm{H}-6$ and the carbons $\mathrm{C}-4$, and $\mathrm{C}-10$ and $\mathrm{C}-7$, also the correlations between the proton $\mathrm{H}-4$ and the carbons C-1', C-5, C- $2, \mathrm{C}-3$ and C- 6 is observed. We also note the correlations of proton $\mathrm{H}-18$ and carbons $\mathrm{C}-12, \mathrm{C}-13$ and $\mathrm{C}-17$. Moreover correlations between the $\mathrm{H}-25$ proton and the $\mathrm{C}-24$ carbon are also observed. Based on these data, and in comparison, with the data of the literature, compound (6) has been identified as $\beta$-sitosteryl palmitate of empirical formula $\mathrm{C}_{45} \mathrm{H}_{78} \mathrm{O}_{2}$ [25], which is isolated from Albizia ferruginea for the first time.

\subsection{Evaluation of Antioxidant Power}

The antioxidant capacity of the compounds is largely dependent on the composition of these compounds as well as the handling conditions of the in vitro tests. To determine the antioxidant activity of the compounds, we used qualitative and quantitative tests of the DPPH method and the FRAP method.

\subsection{Determination of Antioxidant Properties by Trapping the Radical DPPH}

\subsubsection{Qualitative Test}

Chromatograms of the residual and total aqueous ethyl alcoholic extracts were revealed by the methanolic solution of $0.02 \% 1,1$-diphenyl2-picrylhydrazyl. The appearance of yellow-white spots on a purple background made it possible to demonstrate the presence of anti-radical compounds in the extracts tested.

\subsubsection{Quantitative Test}

The antiradical activity was evaluated only on compounds whose chromatogram showed the appearance of yellow-white spots on a purple background. The antiradical activity of these compounds and vitamin $\mathrm{C}$ vis-à-vis the $\mathrm{DPPH}^{*}$ radical was evaluated spectrophotometrically at a wavelength of $517 \mathrm{~nm}$, following the reduction of this radical which is accompanied by its change from the purple color to yellow color. The representation of the antiradical activity as a function of the concentration shows that the compounds have antiradical activities. In addition, the growth of these activities in concentration dependent for each of the compounds tested. We also note that the antiradical activities of these compounds are significantly different $(\mathrm{p}<0.05)$ and are lower than those of vitamin C. However, at the $75 \mu \mathrm{g} / \mathrm{mL}$ dose the entrapment percentage of compound 5 is higher, at doses of 100 and $300 \mu \mathrm{g} / \mathrm{mL}$, compound $\mathbf{6}$ is the highest and finally at the dose of $150 \mu \mathrm{g} / \mathrm{mL}$ is compound $\mathbf{1}$ which is the highest (Fig. 3). Table 3 evaluates the trapping capacity of the DPPH radical of the various Albizia ferruginea compounds.

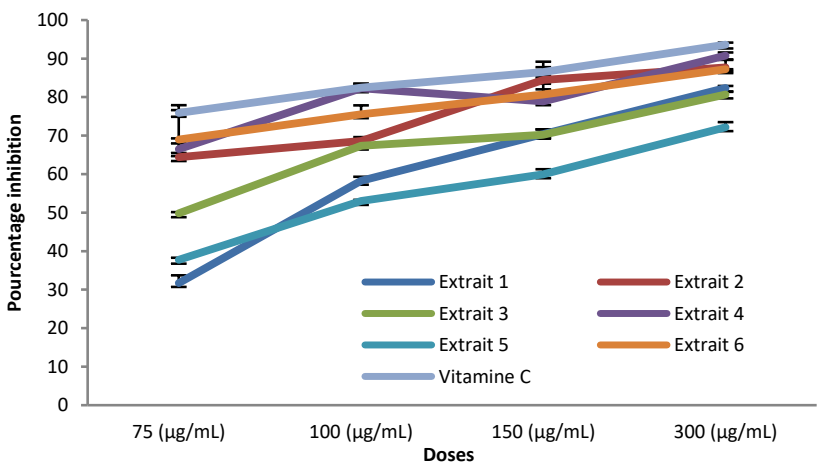

Fig. 3 Trapping capacity of the DPPH • radical of the different compounds of Albizia ferruginea Extract 1: compound (1); Extract 2: compound (2); Extract 3: Compound (3) Extract 4: Compound (4); Extract 5: compound (5); Excerpt 6: Compound (6)

The antioxidant capacity of the various compounds was determined from $\mathrm{IC}_{50}$. It is the effective concentration of compounds that traps $50 \%$ of free radicals. The $\mathrm{IC}_{50}$ and the antioxidant activity of the compounds tested are inversely proportional. The different optical densities made it possible to plot for each compound, the $\mathrm{IC}_{50}$ curve as a function of the concentrations of the compounds, which means the existence of a proportional relationship between the percentage of reduction of the free radical and the concentration of the compounds in the medium reaction. The plot of the $\mathrm{IC}_{50}$ histogram curve of the compounds is shown in Fig. 4. The $\mathrm{IC}_{50}$ values of the different compounds are shown in the Table 4. 
Table 3 Trapping capacity of the DPPH• of various compounds of Albizia ferruginea

\begin{tabular}{lllll}
\hline Compounds & Doses $(\mu \mathrm{g} / \mathrm{mL})$ & & \\
\cline { 2 - 5 } & 75 & 100 & 150 & 300 \\
\hline 1 & $31.71 \pm 5.05$ & $58.25 \pm 1.28$ & $70.39 \pm 0.97$ & $82.36 \pm 1.84$ \\
2 & $64.40 \pm 0.28$ & $68.60 \pm 1.01$ & $84.47 \pm 0.49$ & $87.70 \pm 1.96$ \\
3 & $49.82 \pm 0.31$ & $67.38 \pm 0.31$ & $70.21 \pm 1.41$ & $80.67 \pm 0.81$ \\
4 & $66.49 \pm 10.13$ & $82.27 \pm 1.11$ & $78.9 \pm 10.29$ & $90.78 \pm 0.81$ \\
5 & $37.75 \pm 0.53$ & $53.01 \pm 0.31$ & $59.93 \pm 1.34$ & $72.16 \pm 1.34$ \\
6 & $68.97 \pm 0.31$ & $75.53 \pm 2.32$ & $80.67 \pm 1.34$ & $87.23 \pm 1.92$ \\
Vitamine C & $75.89 \pm 2.01$ & $82.45 \pm 1.06$ & $86.53 \pm 1.23$ & $93.62 \pm 0.53$ \\
F & 44.881 & 254.589 & 16.428 & 75.969 \\
p-value & $<0.0001^{*}$ & $<0.0001^{*}$ & $<0,0001^{*}$ & $<0.0001^{*}$ \\
\hline
\end{tabular}

F: Variable decision of ANOVA, *: Important; (1): (22E, 24S)-Stigmasta-5,22,25-trien3ß-ol; (2): 3 ', 4', 5, 7-tetrahydroxyflavone (luteolin); (3) Quercetin; (4) Kaempferol-7$O$ - $\beta$-D-glucoside; (5) the Acide alphitolic; (6) $\beta$-sitosteryl palmitate

Table 4 IC $_{50}$ values (in $\mathrm{mg} / \mathrm{mL}$ ) of compounds isolated from the roots of Albizia ferruginea

\begin{tabular}{lllllll}
\hline Compd. (1) (2) & (3) & (4) & (5) & (6) & Vitamin C
\end{tabular}

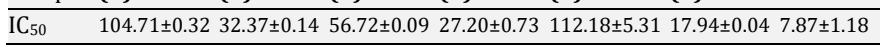

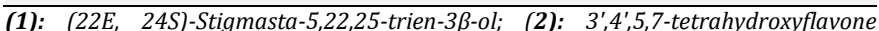
(luteolin); (3) Quercetin; (4) Kaempferol-7-O- $\beta$-D-glucoside; (5) alphitolic acid; (6) $\beta$ sitosteryl palmitate

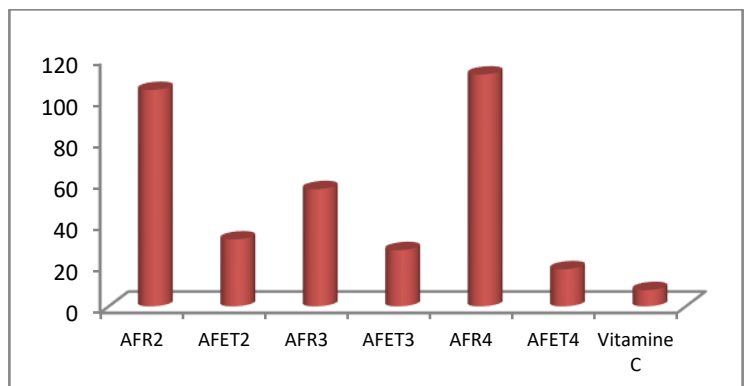

Fig. 4 Histogram of $\mathrm{IC}_{50}$ compounds isolated from the roots of Albizia ferruginea and ascorbic acid dissolved in methanol (AFR2: compound (1); AFET2: compound (2); AFR3: compound (3); AFRT3: compound (4); AFR4: compound (5); AFET4: compound (6))

From the above histogram, we first notice that all our compounds have activities less important than the reference substance, ascorbic acid. Compounds (1) and (2) isolated from the roots of Albizia ferruginea show great activity. The antioxidant activity can therefore be classified within these compounds in descending order as follows: Ascorbic acid> compound (2) >compound (1) Compounds (3) and (4) can be classified in descending order of the anti-radical power, as follows: Ascorbic acid> compound (3) > compound (4) Compounds (5) and (6) can be classified in descending order of the anti-radical power, as follows: Ascorbic acid> compound (5) > compound (6) We observe in these results that whatever the solvent, the isolated compounds of Albizia ferruginea have a high activity.

\subsection{Determination of Total Antioxidant Capacity by FRAP Method}

According to the calibration curve (Fig. 5) and the regression line, the contents recorded in Table 5 are obtained. We observe a reduction of ferric tripyridyltriazine (TPTZ) complex to ferrous tripyridyltriazine when a reducing agent such as an antioxidant substance is present in the compounds. The results of this method are contained in Table 5.

For compounds $\mathbf{1}$ and $\mathbf{2}$ the FRAP values vary respectively between $543.85 \pm 16.91 \mathrm{mg}$ EAA/g MS and 1564.91 $\pm 143.68 \mathrm{mg}$ EAA/g MS. Then for compounds 3 and 4 the values vary between $689.47 \pm 46.77 \mathrm{mg}$ EAA/g MS and $2556.14 \pm 44.76 \mathrm{mg}$ EAA/g MS and finally for compounds $\mathbf{5}$ and $\mathbf{6}$ they vary between $2666,67 \pm 270,08 \mathrm{mg}$ EAA/g MS and 4333,33 $\pm 511,18 \mathrm{mg}$ EAA/G MS. These values make it possible to classify the strength of antioxidant activity according to the isolated compounds of Albizia ferruginea in the following descending order: compound $\mathbf{1}$ has an activity higher than the compound $\mathbf{2}$, by contrast compound $\mathbf{3}$ has an activity higher than compound $\mathbf{4}$ and finally compound $\mathbf{5}$ has an activity greater than compound 6.

This test shows that the roots of Albizia ferruginea are the part of the plant that has the highest antioxidant capacity for this method in the different solvents. Compound $\mathbf{6}$ exhibited the highest antioxidant capacity (4333.33 $\pm 511.18 \mathrm{mg}$ EAA/g MS). In addition, a statistically significant variation of this activity was found between the compounds $(p=0.0058)$.

According to the calibration curve and the regression line, the contents recorded in Table 5 are obtained. We observe a reduction of ferric tripyridyltriazine (TPTZ) complex to ferrous tripyridyltriazine when a https://doi.org/10.30799/jacs.212.19050301 reducing agent such as an antioxidant substance is present in the compounds. The results of this method are contained in Table 5.

For compounds $\mathbf{1}$ and $\mathbf{2}$ the FRAP values vary respectively between $543.85 \pm 16.91 \mathrm{mg}$ EAA/g MS and $1564.91 \pm 143.68 \mathrm{mg}$ EAA/g MS. Then for compounds 3 and 4 the values vary between $689.47 \pm 46.77 \mathrm{mg}$ EAA/g MS and 2556.14 $\pm 44.76 \mathrm{mg}$ EAA/g MS and finally for compounds $\mathbf{5}$ and $\mathbf{6}$ they vary between $2666.67 \pm 270.08 \mathrm{mg}$ EAA/g MS and $4333.33 \pm 511.18 \mathrm{mg}$ EAA/g MS. These values make it possible to classify the strength of antioxidant activity according to the isolated compounds of Albizia ferruginea in the following descending order: compound $\mathbf{1}$ has an activity higher than the compound $\mathbf{2}$, by contrast compound $\mathbf{3}$ has an activity higher than compound $\mathbf{4}$ and finally compound $\mathbf{5}$ has an activity greater than compound 6 .

This test shows that the roots of Albizia ferruginea are the part of the plant that has the highest antioxidant capacity for this method in the different solvents. Compound $\mathbf{6}$ exhibited the highest antioxidant capacity (4333.33 $\pm 511.18 \mathrm{mg}$ EAA $/ \mathrm{g}$ MS). In addition, a statistically significant variation of this activity was found between the compounds $(p=0.0058)$.

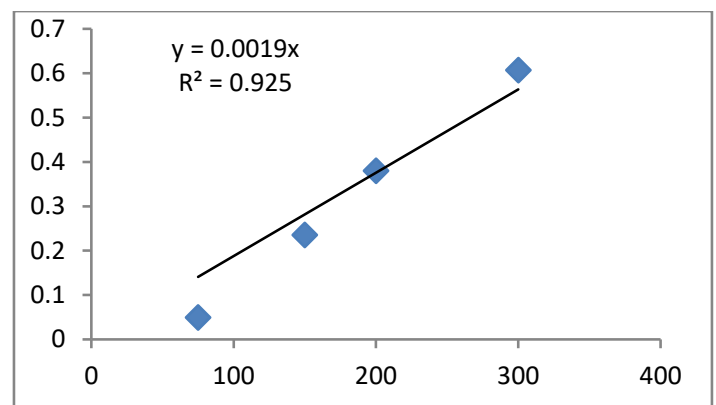

Fig. 5 Vitamin C calibration curve for FRAP

Table 5 Variation in antioxidant capacity

\begin{tabular}{|c|c|c|c|}
\hline Compounds & Averages \pm DS & $\mathrm{H}$ & p-value \\
\hline 1 & $543.85 \pm 16.91$ & & \\
\hline 2 & $1564.91 \pm 143.68$ & & \\
\hline 3 & $689.47 \pm 46.77$ & 16.392 & $0.0058^{*}$ \\
\hline 4 & $2556.14 \pm 44.76$ & & \\
\hline 5 & $2666.67 \pm 270.08$ & & \\
\hline 6 & $4333.33 \pm 511.18$ & & \\
\hline
\end{tabular}

Phytochemical analysis performed on the various extracts reveal the presence of numerous secondary metabolites such as phenolic compounds (tannins, flavonoids, coumarins...), saponins and terpenoids. These results are in agreement with the work carried out in 2014 by Kamga and his collaborators who isolated a new flavone with antioxidant activity and 3 saponins in this plant [10]. According to a study conducted in 2007 by Sokol-letowska [26], some of these secondary metabolites like phenolic compounds (flavonoids and tannins) have an important antioxidant activity due to the presence of many hydroxides that can react with free radicals [27]. The ability of compounds to trap free radicals depends on many parameters; the dose, structure, substituents and degree of polymerization of the molecule. Antiradical activity is very important because of the deleterious role of free radicals in the food and biological systems [27]. The DPPH ${ }^{\bullet}$ radical method used in the present study is a common procedure in which the antioxidant activity of the sample studied is estimated by the degree of discoloration of the DPPH solution. This violet chromogen is easy to use, has high sensitivity, allows rapid analysis of the antioxidant activity of a large number of samples and gives reproducible results [27]. The qualitative test of the $\mathrm{DPPH} \cdot$ radical reduction method performed on the compounds showed numerous antiradical stains on the chromatographic profiles of compounds $\mathbf{1}$ and $\mathbf{2}$. While the quantitative evaluation of the free radical scavenging activity of $\mathrm{DPPH}$ has confirmed that the compounds have an antiradical activity. Nevertheless, the trapping capacity of these compounds remains lower compared to that of vitamin $\mathrm{C}$ ( $\left.\mathrm{IC}_{50}=7,87 \mathrm{mg} / \mathrm{mL}\right)$. According to Souri's classification [28], compound $\mathbf{4}$ has a high potential for antiradical activity $\left(\mathrm{IC}_{50}<20 \mathrm{mg} / \mathrm{mL}\right)$, Compounds $\mathbf{1}$ and $\mathbf{5}$ have a potential for moderate antiradical activity. $\left(20<\mathrm{IC}_{50}<75 \mathrm{mg} / \mathrm{mL}\right)$, compounds 2 and 3 have a low potential ( $\mathrm{IC}_{50}>75 \mathrm{mg} / \mathrm{mL}$ ). The antiradical activity of these compounds can be attributed to the presence of phenolic compounds found in phytochemical analysis because phenolic compounds have been shown to have the ability to yield hydrogen atoms generally associated with the presence of reducing agents [29]. The action of these antioxidants is 
believed to be due to their ability to donate hydrogen or electron atoms derived mainly from the flavonoid ring a hydroxyl [30] and the study conducted by Kamga and collaborators in 2014 highlighted the presence of flavonoids in Albizia ferruginea extracts [10]. The antioxidant effect of flavonoids $(\mathrm{FLOH})$ is attributed to their low redox potential which makes them thermodynamically capable of reducing free radicals $\left(\mathrm{R}^{\cdot}\right)$, by a transfer of hydrogen atom from the hydroxyl groups. This reaction gives rise to the aroxyl radical (FLO') and to the stabilized radical molecule (RH), the $\mathrm{FLO}^{\bullet}$ will subsequently undergo a structural rearrangement allowing the redistribution of the single electron on the aromatic ring and the stabilization of aroxyl radicals [31]. The total antioxidant capacity of our compounds by the ferric reducing antioxidant power (FRAP) method has also been evaluated, ferric tripyridyltriazine (TPTZ) complex reduction to ferrous tripyridyltriazine by these compounds is probably due to the fact that they could reduce the activity. oxidizing free radicals by serving as electron donors. This property could be related to the phenolic compounds present in Albizia ferruginea extracts.

\section{Conclusion}

In this present work, we have investigated the antioxidant effects of compounds isolated from the roots of Albizia ferruginea belonging to the Fabaceae family, used in Cameroonian pharmacopoeia. The evaluation of the antioxidant activity shows that the isolated compounds of this plant and more particularly the roots of Albizia ferruginea would be a potential source of antioxidant substances. A study of the phytochemical composition of the extracts revealed the presence of numerous bioactive chemical compounds known for their biological activities. Our results showed that the tested crude extracts of this plant possess antioxidant activities in vitro. From this study, we can conclude that the extracts from $\mathrm{CH}_{2} \mathrm{Cl}_{2}-\mathrm{MeOH}$ (1:1) mixture of Albizia ferruginea bark roots and the isolated compounds possess interesting antioxidant properties.

\section{Acknowledgement}

The authors thank Department of Biochemistry, Faculty of Sciences of the University of Yaounde I for antioxidant tests.

\section{References}

[1] N.C. Lewise, Study of the phytochemistry and biological activities of two plants used in traditional Gabonese medicine: Terminalia catappa L. (Combretaceae) and Kalanchoe crenata (Andr.) Haw. (Crassulaceae), Thesis submitted for the degree of Doctor in Pharmacy, University of Bamako, Mali, 2007.

[2] S. Rokia, The role of medicinal plants in traditional medicine, Faculty of Medicine of Pharmacy and Odonto-Stomatology, University of Bamako, Mali, 2007.

[3] D.J. MacKay, A.L. Miller, Nutritional support for wound healing, Altern. Med. Rev. 8 (2003) 359-377.

[4] P.G. Pietta, Flavonoids as antioxidants, J. Nat. Prod. 63 (2000) 1035-1042.

[5] E. Middleton, C. Kandaswami, T.C. Theoharides, The effects of plant flavonoids on mammalian cells: implications for inflammation, heart disease and cancer, Pharmacol. Rev. 52 (2000) 673-839.

[6] R. Ksouri, W. Megdiche, A. Debez, H. Falleh, C. Grignon, C. Abdelly, Salinity effects on polyphenol content and antioxidant activities in leaves of the halophyte Cakile maritima, Plant. Physiol. Bioch. 45 (2007) 244-249.

[7] A.B. Aliyu, A.M. Musa, M.A. Ibrahim, H. Ibrahim, A.O. Loyewale, Preliminary phytochemical screening and antioxidant activity of leave extract of albizia chevalieri harms (leguminoseae-mimosoideae), Bayero J. Pure Appl. Sci. 2 (2000) 149-153.

[8] K. Karuppannan, D.P. Subramanian, S. Venugopal, Phytopharmacological properties of Albizia species, Int. J. Pharm. Pharm. Sci. 5 (2013) 70-73.

[9] C. Agyare, G.A. Koffuor, A.Y. Mensan, D.O. Agyemany, Antimicrobial and uterine smooth muscle activities of Albizia ferruginea extracts, Bol. Latinoam. Caribe Plant Med. Aromat. 5 (2006) 31-35.

[10] J. Kamga, P.S. Louis, B.S. Nazli, K. Suheyla, V. Kuete, B.T. Ngadjui, Albiziaflavane A: a new flavane from Albizia ferruginea (Mimosoideae), Nat. Prod. Res. 28 (2014) 1574-1578.

[11] P. Molyneux, The use of the stable free radical diphenylpicrylhydrazyl (DPPH $\left.{ }^{\circ}\right)$ for estimating antioxidant activity, Songklan. J. Sci. Tech. 26 (2004) 211-219.

[12] I.F.F. Benzie, J.J. Strain, Ferric reducing ability of plasma (FRAP) as a measure of antioxidant power: The Frap assay, Anal. Biochem. 239 (1996) 70-76.

[13] K. Hisashi, S. Noriko, H. Akiko, O. Haruo, Sterol glucosides from frunella vulgaris, Phytochem. 29 (1990) 2351- 2355.

[14] A. Toshihiro, T. Toshitake, M. Taro, (22Z,24S)-Stigmastra-5,22,25-trien-3 $\beta$-ol and other novel sterols from Clerodendrum scandens: first report of the Isolation of a cis- $\Delta^{22}$ - unsaturated sterol from a higher plant, J. Chem. Soc. Perkin Trans. 1 (1990) 2013-2018.

[15] S.C. Das, M.N. Qais, M.R. Kuddus, C.M. Hasan, Isolation and characterization of $(22 E, 24 s)$-stigmasta-5,22,25-trien-3 $\beta$-ol from Clerodendrum viscosum vent, Asian J. Chem. 25 (2013) 6447-6448

[16] D.J. MacKay, A.L. Miller, Nutritional support for wound healing, Altern, Med. Rev. 8 (2003) 359-377.

[17] E.S.A.E.G. Afaf, D. Gamal, H. Rehab, Abdallah, H.B. Wafaa, Hassan, A.E.S. Eman, Phytochemical and biological study of Albizia lebbeck stem bark, J. Chem Pharm. Res. 7 (2015) 29-43.

[18] F. Miserez, O. potterat, A. Marston, G.M. Mungai, Kurt, Hostettmann, Flavonol glycosides from Vernonia galamensis sp. Nairobiensis, Phytochem. 43 (1996) 283-286.

[19] E. Wollenweber, V.H. Dietz, Occurrence and distribution of free flavonoid aglycones in plants, Phytochem. 20 (1981) 869-932.

[20] 0.O. Edwin, C.N. Sylvester, 0.0. Patience, O. Lawrence, M. Rakesh, et al., In-vitro anti-inflammatory activities of 3-methoxy quercetin isolated from Nigerian mistletoe parasitic on Garcinia kola Heckel, Clusiaceae, Trop. J. Pharm. Res. 16 (2017) 1059-1067.

[21] Z. Xiaoshu, L. Zhenting, B. Xiuli, L. Jingxin, L. Wei, Z. Yuqing, Flavonoids and its derivatives from Callistephus Chinensis flowers and their inhibitory activities against $\alpha$-glucosidase, Excli. J. 12 (2013) 956-966.

[22] J. Legault, Tommy, Perron, M. Vakhtang, G.L. Karl, et al., Antioxidant and antiinflammatory activities of quercetin 7-0-b-D-glucopyranoside from the leaves of Brasenia schreberi, J. Med. Food. 14 (2011) 1127-1134.

[23] D.P. Gossan, A. Alabdul Magid, P.A. Yao-Kouassi, C.A. Ahibo, J. Josse, et al. Triterpene glycosides from the aerial parts of Gouania longipetala, Phytochem. 134 (2017) 71-77.

[24] S.R. Giacomelli, G. Maldaner, C. Stuker, C. Marasciulo, J. Schmidt, Triterpenoids from Gouania ulmifolia, Planta Med. 73 (2007) 499-501.

[25] S. Jiaming, W. Xiuli, Hui, Y. Junshan, A new triterpenoid ester from Lobelia Sessilifolia, Chem. Nat. Comp. 48 (2012) 416-418.

[26] A. Sokol-Letowska, J. Oszmiansk, A. Wojdylo, Antioxydant activity of the phenolic compounds of Hawthorn, pine and skullcap, Food Chem. 103 (2007) 853-859.

[27] I. Gulcin, Z. Huyut, M. Elmastas, H.Y. Aboul-Enein, Radical scavenging and antioxidant activity of tannic acid, Arab. J. Chem. 3 (2010) 43-53.

[28] E. Souri, G. Amin, H. Farsam, T.M. Barazandeh, Screening of antioxidant activity and phenolic content of 24 medicinal, DARU J. Pharm. Sci. 16 (2008) 83-87.

[29] S.I.R. Hamrouni, F.Z, Ahali, I.B. Rebey, S. Bourgou, F. Limam, B. Marzouk, Total phenolics, flavonoids, and antioxidant activity of sage (Salvia officinalis L.) plants as affected by different drying methods, Food Bioproc. Technol. 6 (2013) 806-817.

[30] K. Le, F. Chiu, K. Ng, Identification and quantification of antioxidants in Fructus lycii, Food Chem. 105 (2007) 353-363.

[31] I. Chevalley, Contribution to the Phytochemical study of Saxifragaceae: Isolation of antioxidants from Saxifraga stellaris L. and Saxifraga cuneifolia L. and an antifungal compound from Ribes rubrum L., Ph.D. Thesis, Lausanne, 2000 